\title{
Independent Signet Ring Cell Carcinoma of the Pancreas: Case Report
}

\author{
Lamyae Nouiakh*, Karima Oualla, Hajar Ouahbi, Soumia Berrad, Hayat Erraichi, Imane \\ Ouafki, Lamiae Amaadour, Zineb Benbrahim, Samia Arifi and Nawfel Mellas \\ Department of Medical Oncology, Hassan II University Hospital, Morocco
}

*Corresponding author: Lamyae Nouiakh, Department of Medical Oncology, Hassan II University Hospital, Fes, Morocco.

To Cite This Article: Lamyae Nouiakh, Karima Oualla, Hajar Ouahbi, Soumia Berrad, Hayat Erraichi. Independent Signet Ring Cell Carcinoma of the Pancreas: Case Report. 2020 - 11(1). AJBSR.MS.ID.001606. DOI: 10.34297/AJBSR.2020.11.001606.

Received: 眥 November 11, 2020; Published: 眥 December 08, 2020

\begin{abstract}
Background: Independent signet ring cell carcinoma of the pancreas is a rare and aggressive histologic variant. We report the case of a patient with independent signet ring cell carcinoma of the pancreas.

Case presentation: 45-year-old men who consulted for epigastralgia associated with subicterus which had progressed for 2 months. Abdominal imaging showed a pancreatic process measuring $7 \mathrm{~cm}$ long axis. A biopsy of the pancreatic mass was performed by duodenoscopy. Pathological examination was in favor of pancreatic independent signet ring cell carcinoma. The decision for palliative chemotherapy was taken collegially in a multidisciplinary consultation meeting. Ten days later, the patient was clinically impaired with installation of cholestatic jaundice and disturbance of liver function tests; hence his hospitalization in the gastrology department for placement of a prosthesis which did not could be done because the patient died following cardio-respiratory arrest.
\end{abstract}

Conclusion: Through our work, we have reported a case of independent signet ring cell carcinoma of the pancreas. It is a rare and aggressive histological form, with few cases published in the literature.

Keywords: Pancreas; Signet ring; Carcinoma

\section{Background}

Pancreatic cancer is a fairly common digestive cancer with a late diagnosis and a severe prognosis due to the late clinical expression of the disease. Pancreatic independent signet ring cell carcinoma is a rare histologic variety [1], characterized by the presence of a monomorphic proliferation of isolated signet ring cells within a mucoid stroma. We report the case of a patient with independent signet ring cell carcinoma of the pancreas.

\section{Case Presentation}

45-year-old men who consulted for epigastralgia associated with subicterus evolving for 2 months. Clinical examination found a patient in average general condition, subicteric with epigastric tenderness, the rest of the somatic examination was unremarkable. The abdominal computed tomography had shown a tumor process of the bilio-pancreatic-duodenal crossroads enhanced heterogeneously after contrast measuring $06 \mathrm{~cm}$ of major axis responsible for a dilation of the intrahepatic bile ducts and the main bile duct of $14 \mathrm{~mm}$ and a discrete dilation of wirsung. There were also latero-aortic, caelio-mesenteric, interaortico-caves lymph nodes measuring for the largest $17 \mathrm{~mm}$. It was completed by a bili-MRI which had objectified a heterogeneous pancreatic tumor process measuring $7 \mathrm{~cm}$ enhancing after contrast, discreetly infiltrating the fat in the periphery responsible for dilation of the common bile duct which measured $1.3 \mathrm{~cm}$ with stop image at the level of its lower part and intrahepatic bile ducts with a slight dilation of the wirsung. A duodenoscopy was performed showing a hemi-circumferential ulcerative process extending to D2 and invading the biopsied papilla.

On anatomopathological examination, the duodenal mucosa was largely dissociated by a polymorphous, lymphoplasmacytic inflammatory granulation tissue with numerous neutrophils 
comprising large cells with fine chromatin and a visible nucleolus with individualization of a few figures of mitosis (Figure 1). The immunohistochemical study confirmed that the large cells

expressed intense and diffuse cytokeratin and MUC1 and focal cytokeratin 7. In addition, CDX2 was negative on tumor cells (Figure 2). a: HES*200

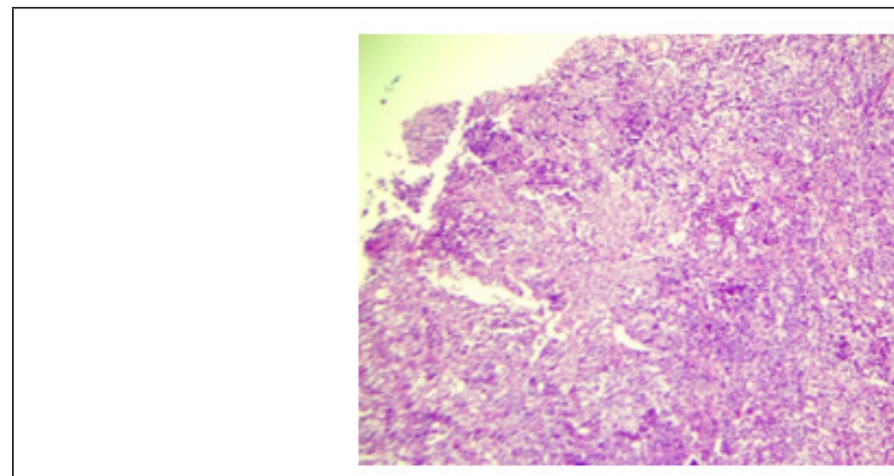

Figure 1a \& 1b: Histological study: the duodenal mucosa was largely dissociated by a polymorphous, lymphoplasmacytic inflammatory granulation tissue with numerous neutrophils comprising large cells with fine chromatin and a visible nucleolus with individualization of a few figures of mitosis.

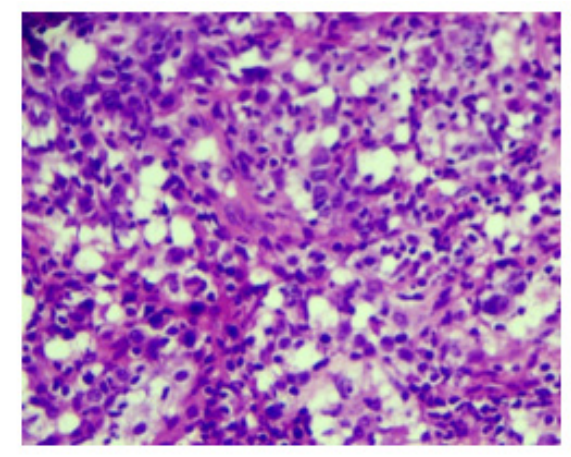

b: HES*400

Figure 2: immunohistochemical study: intense expression of MUC1.

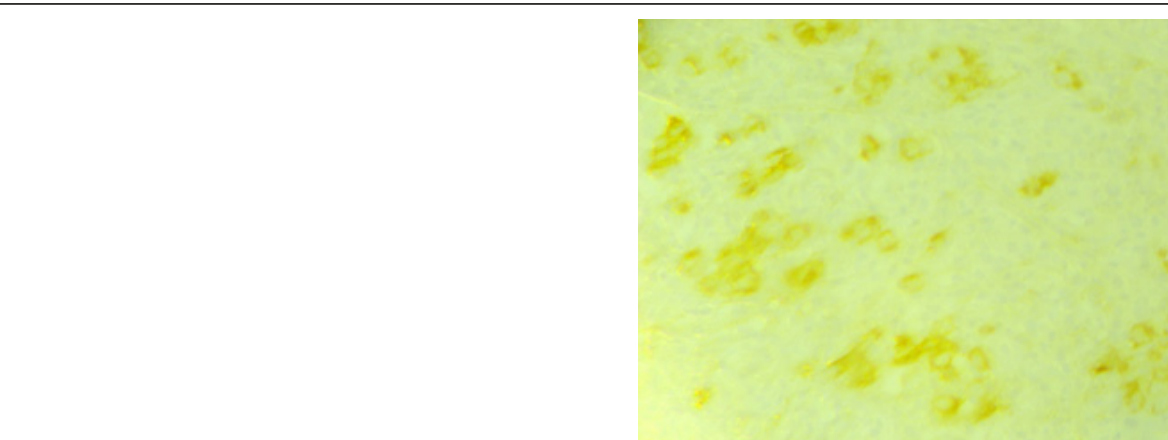

The decision for palliative chemotherapy was taken collegially in a multidisciplinary consultation meeting. Ten days later, the patient was clinically impaired with installation of cholestatic jaundice and disturbance of liver function tests; hence his hospitalization in the gastrology department for placement of a prosthesis which did not could be done because the patient died following cardiorespiratory arrest.

\section{Discussion}

Pancreatic cancer is a fairly common digestive cancer; it is the 10th cancer in men and the 9th cancer in women [2]. The cephalic site is the most frequent anatomical location of pancreatic carcinomas representing $75 \%$ of cases, as in our patient, while 15 to $20 \%$ occur in the body and 5 to $10 \%$ in the tail [2].

Pancreatic adenocarcinoma is the most common histologic type (80\%); on the other hand, the histologic variety of independent signet ring cell carcinoma is rare, representing less than $1 \%$ of pancreatic tumors with only 8 cases that have been reported in the literature. The most frequent location of these rare carcinomas is in the gastric area (96\%) [3], but cases of signet ring cell carcinoma in the colon, gallbladder, appendix, breast, prostate, bladder and thyroid have been reported.

Thoraco-abdominal-pelvic computed tomography (TAP CT) remains the gold standard examination in case of suspected pancreatic cancer, it allows to evaluate the stage and to judge tumor respectability. The recommended protocol $[4,5]$ is an examination tri-phasic by multidetector CT angiography, with a thickness of sections $\leq 0.5-1 \mathrm{~mm}$. In our patient, the TAP CT showed a locally advanced unresectable pancreatic process. The biopsy is not systematic; it is indicated in the event of a tumor potentially resectable by endoscopic ultrasound if neoadjuvant treatment will be considered or in the event of a tumor resectable from the outset if there is doubt about the diagnosis with a benign tumor $[6,7]$. 3 cases among the eight published, the diagnosis was retained post mortem, while the remainder was diagnosed either by endoscopy, retrograde endoscopy or by laparotomy. The table below summarizes the different cases reported in the literature (Table 1). In our patient, the biopsy is performed under duodenoscopy. 
Table 1: The different cases published in the literature of independent signet ring cell carcinoma of the pancreas.

\begin{tabular}{|c|c|c|c|c|}
\hline & Age (year) & Gender & Diagnostic Means \\
\hline Tracey KJ 1984 & 69 & Female & Autopsy \\
\hline Chow LT 1994 & 88 & Male & Echoendoscopy \\
\hline Mc Arthur CP 1995 & 69 & Female & Retrograde endoscopy & - \\
\hline Terada 2012 & 61 & Male & Echoendoscopy \\
\hline Karaahmet F 2015 & 83 & Male & Autopsy \\
\hline Nauta S 2015 & 71 & Male & Tru-cut biopsy \\
\hline Radojkovic M 2018 & 67 & Female & Neoadjuvant chemotherapy (Gemcita- \\
bine) + CDP
\end{tabular}

The therapeutic management of carcinomas with independent signet ring cells joins that of pancreatic adenocarcinomas. The treatment is essentially based on surgery for localized forms; this surgery must be done after a rigorous pre-therapeutic evaluation and within 3 to 4 weeks following the last scannographic evaluation [8]. For cancers of the head of the pancreas, cephalic duodeno-pancreatectomy associated with lymph node dissection by laparotomy is the standard procedure [9]. For metastatic forms; several first-line protocols can be prescribed (FOLFIRINOX, Gemcitabine + nab-paclitaxel, gemcitabine alone) taking into consideration the patient's age, general condition, presence of comorbidities and liver function tests. In our patient, chemotherapy could not be administered due to the rapid deterioration in his general condition.

Pancreatic cancer is a very aggressive cancer with a median survival time of 4 to 6 months. The relative 1-year survival rate is of the order of $28 \%$, with an overall 5-year survival rate of $9 \%$ for all stages [10]. The 5-year relative survival for localized stages is $34.3 \%, 11.5 \%$ for locally advanced stages and $2.7 \%$ for metastatic stages [10]. Independent signet ring cell carcinoma is also a cancer with a poor prognosis [11-15]. All the cases reported had a fulminant evolution, with the exception of a single potentially resectable non-metastatic case which showed the benefit of neoadjuvant chemotherapy with a reduction significant tumor size of $4.5 \mathrm{~cm}$ to $1.5 \mathrm{~cm}$ and which allowed the performance of a radical cephalic duodenopancreatectomy (CDP) [16].

\section{Conclusion}

Through our work, we have reported a case of independent signet ring cell carcinoma of the pancreas. It is a rare and aggressive histological form, with few cases published in the literature, the unfortunate prognosis of this cancer is linked first of all to the aggressiveness of these types of tumors in addition to the diagnostic delay due to the non-specificity and late expression of clinical signs.

\section{Ethics Approval and Consent to Participate}

Not applicable.

\section{Consent for Publication}

Consent from patient was obtained before publication of this case report.

\section{Availability of Data and Materials}

The data are available from the corresponding author on reasonable request.

\section{Competing Interests}

The authors declare that they have no competing interests.

\section{Funding}

The authors received no specific funding for this study.

\section{Acknowledgement}

None.

\section{References}

1. Natesh Y, Rana N, Camille R, Mashaal D, Ajay J (2018) Poorly differentiated signet ring cell carcinoma of pancreas masquerading as chronic pancreatitis. J Surg Case Rep 2018(8): rjy218.

2. Tomislav D, Richard AE (2019) Pancreatic cancer. Medscape, USA.

3. Lee NK, Kim S, Kim HS, Jeon TY, Kim GH, et al. (2011) Spectrum of mucinproducing neoplastic conditions of the abdomen and pelvis: crosssectional imaging evaluation. World J Gastroenterol 17(43): 4757-4771.

4. Al-Hawary MM, Francis IR, Chari ST, Fishman EK, Hough DM, et al. (2014) Pancreatic ductal adenocarcinoma radiology reporting template: consensus statement of the society of abdominal radiology and the american pancreatic association. Gastroenterology 146(1): 291e1$304 \mathrm{e} 1$.

5. Tamm EP, Balachandran A, Bhosale PR, Katz MH, Fleming JB, et al. (2012) Imaging of pancreatic adenocarcinoma: update on staging/resectability. Radiol Clin North Am 50(3): 407-428.

6. Brugge WR, De Witt J, Klapman JB, Ashfaq R, Shidham V, et al. (2014) Techniques for cytologic sampling of pancreatic and bile duct lesions: The Papanicolaou Society of Cytopathology Guidelines. Cytojournal 11(Suppl 1): 2.

7. Okasha HH, Naga MI, Esmat S, Naguib M, Hassanein M, et al. (2013) Endoscopic Ultrasound-Guided Fine Needle Aspiration versus Percutaneous Ultrasound-Guided Fine Needle Aspiration in Diagnosis of Focal Pancreatic Masses. Endosc Ultrasound 2(4): 190-193.

8. Sanjeevi S, Ivanics T, Lundell L, Kartalis N, Andren-Sandberg A, et al. (2016) Impact of delay between imaging and treatment in patients with potentially curable pancreatic cancer. Br J Surg 103(3): 267-275. 
9. Tol JA, Gouma DJ, Bassi C, Dervenis C, Montorsi M, et al. (2014) Definition of a standard lymphadenectomy in surgery for pancreatic ductal adenocarcinoma: a consensus statement by the International Study Group on Pancreatic Surgery (ISGPS). Surgery 156(3): 591-600.

10. NIH (2019) Cancer Stat Facts: Pancreatic Cancer. National Cancer Institute, USA.

11. Piessen G, Messager M, Leteurtre E, Jean-Pierre T, Mariette C (2009) Signet ring cell histology is an independent predictor of poor prognosis in gastric adenocarcinoma regardless of tumoral clinical presentation. Ann Surg 250(6): 878-887.

12. Hyung WJ, Noh SH, Lee JH, Huh JJ, Lah KH, et al. (2002) Early gastric carcinoma with signet ring cell histology. Cancer 94(1): 78-83.

13. Green JB, Timmcke AE, Mitchell WT, Hicks TC, Gathright JB, et al. (1993) Mucinous carcinoma--just another colon cancer? Dis Colon Rectum 36(1): 49-54.
14. Nissan A, Guillem JG, Paty PB (1999) Signet-ring cell carcinoma of the colon and rectum: a matched control study. Dis Colon Rectum 42(9): 1176

15. Psathakis D, Schiedeck TH, Krug F, Oevermann E, Kujath P, et al. (1999) Ordinary colorectal adenocarcinoma vs. primary colorectal signet-ring cell carcinoma: study matched for age, gender, grade, and stage. Dis Colon Rectum 42(12): 1618.

16. Radojkovic M, Ilic D, Ilic I (2017) Primary signet ring cell carcinoma of the pancreas with a good response to chemotherapy: case report and literature review. Tumori 103(Suppl 1): e50-e52. 